that must be complied with for fear of legal consequences. Instead, an Ombudsman makes recommendations, which may or may not be complied with. Naturally, my fellow Ombudsmen and I expect that in most cases our recommendations will be complied with, and in fact in $99 \%$ of cases that expectation turns out to be justified. Nevertheless, it remains open to a public authority to refuse and to face the music instead. The Ombudsman has, to put it in the jargon, a 'mandate of influence' rather than a 'mandate of sanction'.

A mandate of influence of this sort can, outside the legal or disciplinary process, work very effectively in practice. In one recent case investigated by my office, a staff-grade psychiatrist for older people decided to withdraw an antidementia drug from an elderly patient. My investigation uncovered a failure to communicate significant changes in the patient's treatment plan to those members of the family most closely involved in the patient's care, and the omission of any planning for deterioration. This was not a case of the clinical decision itself being wrong, but rather of a failure to see the bigger picture of which that clinical decision formed just one part. As a result, the trust in question agreed to apologise to the patient and family and to remind senior medical staff of the importance of careful monitoring of patients where medication is discontinued. The trust also agreed to conduct an audit of 'consensus-meeting documentation' to ensure that this format was properly used in future and that the requisite level of information was recorded.

Another case concerned the treatment of an adolescent girl with anorexia nervosa, who regularly absconded from hospital and whose parents despaired of the level of treatment offered to her, even to the extent of removing her to private care after 18 months with the National Health Service. My investigation found that the adolescent unit had inadequate systems in place for care planning, communication, risk assessment and risk management. These omissions denied the patient and her family any real sense of engagement in her treatment. As a result, she lost weight and her health and safety were compromised. The trust in question apologised, paid compensation for distress and reimbursed the full cost of the private treatment incurred. Just as importantly, the trust also ensured that it would in future have clear policies that could be shared with patients and their families, and that it would implement the latest national clinical guidelines on eating disorders.

These examples reinforce my view that exposure to complaints should not be a source of professional trepidation. The process of complaining should instead be seen as part of the necessary dialogue between patient, professional healthcare staff and the healthcare 'system' as a whole. It is, in other words, part of the process for diagnosing the state of those healthcare services and prescribing the proper remedial treatment. At its best, it is nothing less than a 'talking cure' in action, the Ombudsman cast in the role more of therapist than of judge. Which is not to say that there will not be a place for 'tough love' on occasions. But it is to say that the whole business is ultimately about a shared quest for excellence much more than the unilateral ascription of individual blame.

\title{
Mental health and poverty
}

\section{David Skuse}

Behavioural and Brain Sciences Unit, Institute of Child Health, London WC1N 1EH, UK, email dskuse@ich.ucl.ac.uk

W e are all too well aware that there is a link between poverty and mental health in the Western world, which can work in two directions: those with low incomes are more likely to suffer from poor mental health; and people with mental health problems are more likely to experience poverty. In this issue, we consider the link between poverty and mental health from the perspectives of the Caribbean, East Africa and Mexico. In each situation, the relationship between them is complex and dynamic.

Fred Hickling challenges us to consider the possibility that the legacy of colonial rule in the Caribbean has led to a political and economic system that ignores the potential contribution of its most talented citizens, and which engenders a sense of helplessness and hopelessness that can lead to violent crime and mental disorder. Those who escape from this legacy (the so-called Caribbean Diaspora) find little comfort in their hoped-for paradise in Europe or the United States, and are at greater risk of developing mental illness there than is the indigenous population. He concludes that 'poverty has become too costly to maintain for any society' a challenging view indeed.

Fred Kigozi and Joshua Ssebunnya draw our attention to the troubles of East Africa (that cluster of countries around Lake Victoria). In an area of 130 million $\mathrm{km}^{2}$, there are fewer than a dozen psychiatrists. The population is growing rapidly and poverty is increasing. In the countries comprising this region, there have been and continue to be terrible wars and internal conflicts - especially in Rwanda and Uganda. To make matters worse, refugees from beyond their borders are coming in. Not surprisingly, many of these refugees have major mental health problems associated with their experiences and the trauma of dislocation. Objective evidence 
of post-traumatic stress disorder affecting more than half the adult population in some areas of East Africa has been adduced. How to begin to cope with that mental health burden is an urgent question for those countries affected and for the international community of psychiatrists with an interest in the region. What resources are available, or could be made available, to alleviate the suffering of these people? Dr Kigozi is involved in a mental health and poverty project that has produced a detailed account of services and need in Uganda, in collaboration with the WHO (see http:// workhorse.pry.uct.ac.za:8080/MHAPP/public/index_html); it is to be hoped similar reports - serving as the basis for action in adjacent countries - could be prepared too.

Finally, we move across the Atlantic to Mexico and the concerns expressed by Shoshana Berenzon and colleagues that the extreme inequity of income distribution in Latin
America is responsible for engendering mental health disorders. After Brazil, Mexico has the largest economy in Latin America and is undergoing rapid development, yet one in six of the population lives in extreme poverty, without easy access to sanitation or drinking water, and many of these people are in urban areas. The reason for much mental illness, according to the surveys reviewed by the authors, is the relative socioeconomic status of the sufferer, who feels unable or unwilling to seek professional help - even if that help is potentially available. The authors point out that there may be quite a discrepancy between the perceived needs of the population suffering from the consequences of extreme poverty and the relatively academic approach to the assessment and treatment of mental illness by professionals. This is, of course, an issue that is not peculiar to Mexico, and bears on a critical aspect of the theme addressed by all our contributors.

\section{The high cost of poverty: mental health perspectives from the Caribbean Diaspora}

\section{Frederick W. Hickling DM MRCPsych(UK) DFAPA}

Professor of Psychiatry, Department of Community Health and Psychiatry, University of the West Indies, Mona, Kingston 7, Jamaica email frederick.hickling@uwimona.edu.jm

\begin{abstract}
'Globalization is an objective reality - underlying the fact that we are all passengers on the same vessel - the planet where we all live.' (Fidel Castro, 2000, p. vii)
\end{abstract}

Caribbean Diaspora has emerged worldwide after 500 years of European colonial exploitation of the Caribbean geopolitical region. This exploitation has a two-tiered social legacy: the 'haves'; and the 'have-nots', characterised by poor educational achievement, underdevelopment and unemployability of the many. The Caribbean Diaspora is a product of ever-increasing fantasies of escape from poverty by migration to greener 'First World' pastures. The complex, contradictory Caribbean society generates a crucible of misery and violence amid opulent wealth and luxury, which requires a burgeoning private and public police and military apparatus for its containment, and an ever-increasing health, mental health and penal correctional system to buttress the casualties of this conflict that is spiralling out of organisational and economic control. This two-tiered society was inherited from the hierarchical legacy of European colonialism. The colonisers existed in a system of high productivity and order, which imposed its will on the colonised, who lived in relative disorganisation and need. The resultant vector of this unequal yoke is the virtual anarchy of present-day Jamaica and other Caribbean territories, characterised by a subculture of violence and increasingly violent crime. The physical, psychological and economic costs of this seeming conundrum are bewildering and unaffordable.

The dialectic relationship between European wealth and African (and other) poverty is inescapable. In a recent study, Nunn (2007) concluded that slavery played an important role in Africa's underdevelopment; for example, the largest numbers of slaves were taken from areas that were most underdeveloped politically at the end of the 19th century and these areas are the most ethnically fragmented today. Without the slave trade, $72 \%$ of Africa's income gap with the rest of the world would not exist today. In a landmark study, Jamaican economist George Beckford (1972) identified that Latin America and the Caribbean, Africa and Asia, popularly described as the 'Third World', although vast in area and rich in resources, do not provide adequate levels of living for their populations. Beckford suggested that the dynamics of underdevelopment - both of the plantation economy and of society - form the basis for 'persistent poverty' for low- and middle-income countries and economies.

There is an increasingly strident discourse that is demanding a contemporary worldwide resolution of this dialectic of underdevelopment. This is inevitable in the global transformation that is required for the resolution of the crisis of global capitalism. A study by Trinidadian economist Eric Williams (1944) established that African slavery was the midwife to industrialisation in Europe and the slave trade was abolished in order to broaden the base of the global market 